\title{
JORGE ANÍBAL FLORES OCHOA, YACHAYRUNA (1935-2020)
}

\author{
Héctor González Cortez ${ }^{1}$
}

A las 10:09 del pasado jueves 20 de agosto el diario La República del Perú de Lima informó por las redes sociales la triste noticia del fallecimiento de Jorge Aníbal Flores Ochoa en el Cusco ${ }^{1}$.A la edad de 85 años, había perdido la lucha contra el coronavirus después de permanecer internado por más de una semana en la Unidad de Cuidados Intensivos del hospital público de la ciudad. La antropología latinoamericana había perdido a uno de sus más destacados exponentes y la revista Chungara a uno de los miembros más distinguidos de su comité asesor. Ciertamente, nuestro sentimiento no se iguala al dolor de su familia, de su esposa, la también antropóloga Yemira Nájar, y de sus hijos, a quienes transmitimos nuestras condolencias y afecto.

Jorge Flores Ochoa nació en el Cusco en enero de 1935, siendo sus padres el abogado don Miguel Ángel Flores Fernández y doña Ildaura Ochoa Pacheco, ambos descendientes de familias con haciendas en Paucartambo y en Urubamba, respectivamente. Su infancia y adolescencia transcurrió en el tradicional barrio de San Pedro de la ciudad y en el Colegio Salesiano. Sus estudios superiores los cursó en la Universidad Nacional San Antonio Abad del Cusco (UNSAAC), donde obtuvo su bachillerato en derecho en 1960, su graduación en antropología en 1965 y su doctorado en Letras y Ciencias Humanas en 1967. También realizó estudías postdoctorales en la Universidad de Cornell y en la Universidad de California Berkeley. En 1964 fue contratado en la Universidad Técnica del Altiplano en Puno (hoy Universidad Nacional del Altiplano). Un par de años después retornó al Cusco para incorporarse a la UNSAAC, donde fue el primer director del Programa Académico de Antropología. En esta universidad se mantuvo casi por cinco décadas, ocupando diversos cargos, incluidos los más altos de Vicerrector Académico y de Rector a.i. en 1998. Fue conferencista y profesor invitado en diferentes universidades del mundo y trabajó en la Universidad de California Berkeley entre 1976 y 1977.

Durante su estadía en Puno, realizó su trabajo de campo entre los pastores de Paratía, que por sobre los 4.000 de altura solo se dedicaban a la ganadería, material que utilizaría para la elaboración de su tesis doctoral de 1967. La importancia de este trabajo fue advertida por John Rowe y su esposa Patricia Lyon, que frecuentaban regularmente el Cusco y su Universidad, quienes lo alentaron y aconsejaron para su término ${ }^{2}$. John Murra, quien curiosamente en un trabajo de 1964 sobre rebaños y pastores durante el incanato había señalado que antes de la invasión hispana no había en los Andes una economía puramente pecuaria, al conocer el trabajo de Flores Ochoa supo reconocer su importancia para que fuese publicado como monografía por el Instituto Indigenista Interamericano en 1968, transformándose en un clásico de la antropología andina. Como señala Ralph Bolton en su nota como traductor de la obra al inglés en 1979, ella no solo era importante por su aporte a la compresión de la diversidad cultural andina y por sugerir que este modo de subsistencia podía ser antiguo en los Andes, sino también por su impacto sobre el conocimiento de las sociedades pastoriles en la época, ya que se había asumido que el pastoreo como estrategia económica predominante o exclusiva solo estaba presente en el Viejo Mundo, en el Medio Oriente, África Oriental, Asia Central y el norte de Escandinavia, y que entre los Navajo, la única sociedad pastoril descrita en el Nuevo Mundo era resultado de la introducción de ovejas después de la conquista europea.

$\mathrm{El}$ interés de Jorge Flores Ochoa por el pastoreo altoandino se tradujo en la edición de otras dos obras sobre tema, donde incluyó estudios de diferentes autores sobre el tema. Pero no solo se interesó por las poblaciones ganaderas de altura desde el punto de vista estrictamente económico, sino también sobre otros aspectos de su vida social y religiosa. Estos ya estaban presentes en su trabajo sobre Paratía, en particular sobre los conjuntos de músicos presentes en las fiestas (los ayarachis), pero son tratados más ampliamente en su trabajo de 1974 sobre las ceremonias mágico-religiosas en las que intervienen la enqa, el enqaychu, la illa o la khuya rumi, donde también postula la íntima relación entre los pastores de puna con el Tawantinsuyo. Es necesario mencionar que su obra es muchísimo más amplia y su aporte a la literatura antropológica andina

\footnotetext{
${ }^{1}$ Departamento de Antropología, Universidad de Tarapacá, Arica, Chile.
} 
no sólo se limita al mundo de los pastores, sino que abarca también en general diversos temas históricos y antropológicos de la región cusqueña. De todas maneras, si Jorge Basadre G., acuñó el concepto del "Perú profundo" (inspirado en la Francia profunda, la de los antepasados anónimos, de Charles Péguy), a Jorge Flores Ochoa ciertamente le debemos tal vez la introducción de otro concepto, el de "Perú de altura". Pocos años atrás, en ocasión de la celebración de los cincuenta años de la publicación de Los Pastores de Paratía, todavía reclamaba: "El Perú oficial ignora a los pastores de llamas y alpacas. El Perú oficial sigue creyendo que la puna es la zona más pobre del Perú, pero lo cierto es que está empobrecida por un sistema económico y educativo que no la entiende".

Afortunadamente, a diferencia de otros casos, Jorge Flores Ochoa alcanzó a recibir en vida los más altos reconocimientos en su ciudad y de su país, no solo por sus aportes antropológicos, sino también por su contribución a la valoración de la centralidad del Cusco y la cusqueñidad. No solo fue un amauta de la disciplina, como lo recuerdan sus amigos y alumnos, fue también un personaje local muy querido y celebrado entre sus conciudadanos, quienes, con ocasión de su partida, de diferentes maneras y en diversos medios han evocado su ejemplar sabiduría, dedicación y humildad.

\section{Notas}

\footnotetext{
${ }^{1}$ Tristemente, pocos días después, el 30 de agosto fallece por la misma causa Ricardo Valderrama Fernández, otro gran antropólogo cusqueño, quien en ese momento se desempeñaba como alcalde de la ciudad.

${ }^{2}$ Rowe, el gran estudioso de la cultura Inca, fundó en 1946
}

la sección de arqueología de la Universidad de San Antonio Abad y fue al mismo tiempo director del Museo e Instituto de Arqueología, que después se convertiría en Museo Inka, que también fue dirigido y asesorado permanentemente por Jorge Flores Ochoa. 